\title{
Can Recovery-Oriented Mental Health Services be Created in Hong Kong? Struggles and Strategies
}

\author{
Samson Tse - Bonnie Wei Man Siu • \\ Alice Kan
}

Published online: 13 December 2011

(C) The Author(s) 2011. This article is published with open access at Springerlink.com

\begin{abstract}
Recovery has been adopted as either the national policy or guiding principle for reforming mental health services in many countries. Development and implementation of the concept of recovery is still in its infancy in most Asian countries, and Hong Kong is no exception. The present authors propose three strategies to guide the transformation of Hong Kong mental health services toward becoming more recovery-oriented.
\end{abstract}

Keywords Chinese mental heatlh $\cdot$ Culture $\cdot$ Asia ·

Psychiatric rehabilitation

\section{Introduction}

Concepts of recovery represent sets of principles and theories of practice based on an accumulation of research over two decades, most of which has been conducted in Englishspeaking, high-income countries such as the United States, United Kingdom, and New Zealand (Slade and Hayward 2007; Tse and Barnett 2008; Warner 2010). There are

S. Tse $(\bowtie)$

Department of Social Work and Social Administration, Faculty of Social Sciences, The University of Hong Kong, Room 1326, 13/F, K.K. Leung Building, Pokfulam Road, Hong Kong, Hong Kong

e-mail: samsont@hku.hk

B. W. M. Siu

Castle Peak Hospital, Tuen Mun, New Territories, Hong Kong e-mail: bonniew114m@yahoo.com

\section{A. Kan}

Department of Social Work and Social Administration, Faculty of Social Sciences, The University of Hong Kong, Hong Kong, Hong Kong

e-mail: alicekan888@yahoo.com many definitions of recovery in the literature. For example, one study of first-episode patients in recovery from bipolar disorder reported that $98 \%$ of the sample achieved syndromal recovery, defined as no longer meeting the diagnostic criteria of the illness within 2 years, compared to only $38 \%$ achieving functional recovery, or regaining the life roles they had enjoyed prior to the onset of illness (Tohen et al. 2000). Concepts or models of recovery are diverse (Davidson et al. 2010); Henderson 2010; Jacobson and Greenley 2001; Starnino 2009). A good example is the integrated sociological model of recovery which postulates that demographic factors (such as age and gender) and social roles are associated with the onset of mental illness, and being able to recognize the symptoms and cope with stigma will have positive consequences for general well-being (Ralph and Corrigan 2005). The present authors define recovery as the process and outcomes by which and in which a person with psychiatric disability regains his/her level of functioning (the "being"), sense of hope for future (the "becoming"), and connection with oneself and others (the "belonging"). The link between process and outcome does not operate in a simple, linear fashion; nor should they be seen as two opposite ends of a spectrum, but rather as concepts that mutually interact as the person's journey to recovery unfolds. We consider that recovery has to be initiated, driven, and endured by the person him/herself, while professionals and the mental health system can provide a recovery-enhancing environment. The boundary between the person's subjective experience and the recovery environment is therefore somewhat arbitrary.

Development and implementation of the recovery concept is still in its infancy in most Asian countries, and Hong Kong is no exception. Hong Kong is one of the most densely populated areas in the world. It has a population of 7 million people, of whom $95 \%$ are Chinese and 5\% from 
Table 1 Mental health professionals and populations (Lo et al. 2005; World Health Organization 2005)

${ }^{a}$ Unlike other jurisdictions in the Table, Hong Kong is not a country, is a Special

Administrative Region of China

\begin{tabular}{lllllll}
\hline & Hong Kong $^{\text {a }}$ & Singapore & Japan & $\begin{array}{l}\text { United } \\
\text { Kingdom }\end{array}$ & $\begin{array}{l}\text { United } \\
\text { States }\end{array}$ & New Zealand \\
\hline $\begin{array}{c}\text { Percentage of GDP invested } \\
\text { in mental health services }\end{array}$ & 0.2 & 0.3 & 0.4 & 0.6 & 0.8 & 0.9 \\
$\begin{array}{c}\text { Psychiatrists per 100,000 } \\
\text { population }\end{array}$ & 2 & 2 & 9 & 11 & 14 & 7 \\
$\begin{array}{c}\text { Psychologists per } \\
100,000 \text { population }\end{array}$ & Not available & 1 & 7 & 9 & 31 & 28 \\
$\begin{array}{c}\text { Social workers per } \\
100,000 \text { population }\end{array}$ & NA & 3 & 6 & 58 & 35 & NA \\
\hline
\end{tabular}

other ethnic origins. Hong Kong has a gross domestic product (GDP) of US\$301.6 billion of which approximately $5.5 \%$ is spent on health care and about $0.2 \%$ on mental health care (World Health Organization 2005); (Table 1). The government is the major provider of mental health care through the Hospital Authority, a statutory body that manages all public hospitals in Hong Kong. (Cheung et al. 2010) note that:

To cope with the ever increasing demand as the population becomes more aware of mental health problems, the service has evolved, over time, into a highly efficient system, characterized by high service throughput and efficient management of patients, but with a focus on risk aversion rather than personalised care. (p. 63).

As far as the practice and policy context around recovery are concerned, Hong Kong is just embarking on a journey.

\section{Recovery Studies in Hong Kong}

Over the years, various studies on recovery have been conducted in Hong Kong. In 2005, Yip discussed the concept of strengths-based therapy, a recovery-oriented intervention for people affected by addiction (Yip 2005). (Lam et al. 2010; Ng et al. 2011; Ng et al. 2008) published a series of articles on the meaning of recovery, focusing on people in recovery from schizophrenia and first-episode psychosis, that was based on the perceptions of service users, medical students, and trainee psychiatrists. The major themes in these articles include control of psychiatric symptoms, sense of normalcy, reduced use of medications, and dealing with stigma associated with persistent mental illness. These findings represent a significant step forward in capturing users' personal accounts of the recovery experience. In a similar vein, Kwok was the first Hong Kong native to share in the psychiatric literature the very moving testimony of her recovery from bipolar illness (Kwok 2009); she also revealed her experiences in a book titled Free to fly: A story of manic depression. Chiu and his colleagues performed the first empirical study to investigate the feasibility of recovery concepts among Chinese people affected by schizophrenia spectrum disorders (Chiu et al. 2010). They conclude that the 10 guiding principles adopted by the Substance Abuse and Mental Health Services Administration (SAMHSA) in the United States seem to contain cross-culturally valid concepts for Chinese service users, and that resilience, respect, empowerment, and the impact of stigma are as important as the control of symptoms in determining recovery. Expanding the focus from service users' recovery experiences to workforce development, Mak and her colleagues conducted a staff survey within one of the major community mental health nongovernmental organizations in Hong Kong and found that there was a need for staff training in the understanding of recovery and the implementation of recovery principles (Mak et al. 2010). Given that there is no single concept of recovery in the literature, the authors can only make a tentative comparison between the Western concept and the work now emerging in Hong Kong. It seems that in many cases, the differences are more a matter of relative emphasis than fundamental disagreement; for example, Hong Kong service users seem to place strong emphasis on the control or disappearance of symptoms and reclaiming life roles in work or study. For Chinese service users, it seems that recovery is often seen more as an outcome (for example, the person asks "have I recovered?") than a process (such as "what is my recovery journey?").

\section{From Struggles to Strategies: The Second Decade of the Twenty-First Century}

Based on a review of relevant literature (Anthony 1993; Bond et al. 2010; Frese et al. 2001) and the authors' own reflections, three strategies are proposed to guide the transformation of Hong Kong mental health services toward becoming a recovery-oriented environment. The structure and order of the proposed framework has been endorsed in a discussion involving 16 health professionals (comprising nurses, psychiatrists, social workers, and occupational therapists). 
Gain an In-Depth Understanding of the Concepts of Recovery in the Context of Chinese Communities

The first task is to gain an in-depth understanding of the concepts of recovery in a cultural context. To date, there is neither an official translation of the word "recovery" nor a careful cultural discourse on the concept within Chinese communities in Hong Kong. One translation is 復元 (fu yuan), which is a colloquial phrase found in the ancient Chinese text titled Yi-jing (易經) (V. Cheng, personal communication, Sept 29, 2011). Yuan (元) is the primordial "qi" meaning energy, vitality, or the driving forces in life. Thus, the phrase "recovery" in Chinese means "regaining vitality and the life-driving force." For individuals in recovery from mental illness, because of the physical, psychological, and social barriers they encounter, their "qi" has long been strangled. All these barriers are culturally bound (Tse et al. 2010). In order to capture a broad scope of opinions and experiences about recovery, service users' age, gender, and history of illness should also be considered. Thus, another pressing task is to investigate systematically what facilitates and hinders recovery for individuals at different stages of their journey in the context of Hong Kong, where psychiatric illness remains strongly taboo and only limited resources are allocated to mental health services (see Table 1). As Chinese people place a strong emphasis on collectivism and the maintenance of harmony, and as up to $80 \%$ of individuals with psychiatric disability are looked after by loved ones at home (Sun 2008; Yip 2004), it is pivotal to investigate how recovery is redefined and negotiated by individuals in recovery and, importantly, by their family members and caregivers.

\section{Grow Leaders from Within the Service User Communities}

In most of the countries adopting concepts of recovery in their health services, there are many prominent individuals behind the movement (some examples are Deegan 2010 and O'Hagan 2009). The meaningful involvement of users in mental health care is considered one of the hallmarks of recovery-oriented services. In Hong Kong, the early signs are that the "recovery movement," if there is one, has been initiated and promoted by health professionals with limited input from user communities (Tse et al. (in press)). The notion that individuals recovering from mental illness could participate in and provide useful inputs to mental health services is based on two basic premises. First, users "might better identify or understand the issues associated with mental illness arising for their peers and make unique contributions because of their personal experience" (Doughty and Tse 2010, p. 252). Second, users could share their perspective gained from first-hand experience to facilitate changes in public attitudes to mental illness and within mental health systems. Trained service users can provide effective services through performing a variety of roles such as facilitators of peer-support groups, peer support workers, educators, researchers, service auditors, service planning advisors, and advisors on mental health policy (Davidson et al. 2005; Doughty and Tse 2010; Wood and Wahl 2006).

\section{Develop a Scale to Measure Recovery}

After progress has been made to deepen cultural understanding of the recovery concept, practitioners and researchers should endeavor to develop a scale that can capture the unique features of local practice in Hong Kong. The two main directions of scale development are to differentiate the stages of recovery beyond the limits of disability (Andersen et al. 2003; Corrigan et al. 2004) and measure to what extent mental health practices adhere to the recovery principles (Campbell-Orde et al. 2005; Ridgway et al. 2003). Instead of reinventing the wheel, one can build on credible work for example, a recently published measure called the Stages of Recovery Scale, which appears to have overcome most of the limitations of existing recovery-related instruments (Song and Hsu 2011). Emerging evidence from a Taiwan rehabilitation sample supports the scale's internal consistency, factor structure, external construct validity, and discriminant validity across stages of recovery. It appears to be psychometrically sound for measuring both the processes and outcomes of recovery, and for documenting the evidence of a recovery-oriented program.

\section{Conclusions}

This viewpoint article seeks to stimulate discussion among service users, concerned parties, practitioners, policy makers, and the general public in Hong Kong about what has already been accomplished and what else needs to be in place to implement the concept of recovery. While the three strategies outlined here are applicable not only in Hong Kong but also across many jurisdictions, they can provide mental health services in Hong Kong with a clear framework within which to advance their work in a sustained and programmatic fashion. The authors cannot agree more with Slade and Hayward (2007), who argue that it is important to establish demonstration sites to develop and evaluate recovery-oriented interventions: "two key questions for these demonstration sites will be whether recovery-focused services actually promote recovery and whether recoveryfocused services also lead to improvement in professionallydefined domains of outcome (e.g., improved employment outcomes, quality of life)" (p. 82, emphasis added). 
Nevertheless, we would assert that demonstration sites can benefit tremendously by having meaningful input from service users throughout the design and implementation phase. To conclude, moving forward into the second decade of the 21st, we have learnt from our struggles and are ready to begin implementing the strategies for putting the concept of recovery into practice in Hong Kong.

Open Access This article is distributed under the terms of the Creative Commons Attribution Noncommercial License which permits any noncommercial use, distribution, and reproduction in any medium, provided the original author(s) and source are credited.

\section{References}

Andersen, R., Oades, L., \& Caputi, P. (2003). The experience of recovery from schizophrenia: Towards an empirically validated stage model. Australian and New Zealand Journal of Psychiatry, $37,586-594$

Anthony, W. (1993). Recovery from mental illness: The guiding vision of the mental health service system in the 1990's. Psychosocial Rehabilitation Journal, 16(4), 11-23.

Bond, G. R., Drake, R. E., \& Becker, D. R. (2010). Beyond evidencebased practice: Nine ideal features of a mental health intervention. Research on Social Work Practice, 24, 1-9.

Campbell-Orde, T., Chamberlin, J., Carpenter, J., \& Leff, H. S. (2005). Measuring the promise: A compendium of recovery measures, vol. II. Cambridge: Human Services Research Institute.

Cheung, E. F. C., Lam, L. C. W., \& Hung, S.-F. (2010). Mental health in Hong Kong: Transition from hospital based service to personalised care. International Psychiatry, 7(3), 62-64.

Chiu, M. Y. L., Ho, W. W. N., Lo, W. T. L., \& Yiu, M. G. C. (2010). Operationalization of the SAMHSA model of recovery: A quality of life perspective. Quality of Life Research, 19, 1-13.

Corrigan, P. W., Salzer, M., Ralph, R. O., Sangster, Y., \& Keck, L. (2004). Examining the factor structure of the recovery assessment scale. Schizophrenia Bulletin, 30, 1035-1041.

Davidson, L., Chinman, M. J., Kloos, B., Weingarten, R., Stayner, D. A., \& Tebes, J. K. (2005). Peer support among individuals with severe mental illness: A review of the evidence (pp. 412-450). Boston: Boston University Center for Psychiatric Rehabilitation.

Davidson, L., Rakfeldt, J., \& Strauss, J. S. (2010). The roots of the recovery movement: Lessons learned. London: Wiley-Blackwell.

Deegan, P. E. (2010). A Web application to support recovery and shared decision making in psychiatric medication clinics. Psychiatric Rehabilitation Journal, 34(1), 23-28.

Doughty, C., \& Tse, S. (2010). Can consumer-led mental health services be equally effective? An integrative review of CLMH services in high-income countries. Community Mental Health Journal, 47(3), 252-266.

Frese, F. J., Stanley, J., Kress, K., \& Vogel-Scibilia, S. (2001). Integrating evidence-based practices and the recovery model. Psychiatric Services, 52(11), 1462-1468.

Henderson, A. R. (2010). A substantive theory of recovery from the effects of severe persistent mental illness. International Journal of Social Psychiatry, 57(6), 564-573.

Jacobson, N., \& Greenley, D. (2001). What is recovery? A conceptual model and explication. Psychiatric Services, 52, 482-485.

Kwok, C. F.-Y. (2009). My journey to wellness. Psychiatric Rehabilitation Journal, 32(3), 235-236.

Lam, M. M., Pearson, V., Ng, R. M., Chiu, C. P., Law, C. W., \& Chen, E. Y. (2010). What does recovery from psychosis mean?
Perceptions of young first-episode patients. International Journal of Social Psychiatry, doi:10.1177/0020764010374418.

Lo, T. L., Chan, S. Y., Chung, K. F., Hung, S. F., Lam, L., Leung, S. P., et al. (2005). Submission of the Hong Kong College of Psychiatrists to the Hong Kong Academy of Medicine on medical manpower planning.

Mak, W., Lam, B., \& Yan, S. (2010). Recovery knowledge and recovery-oriented services in Hong Kong. Psychiatric Services, $61,1164$.

Ng, R. M., Pearson, V., Chen, E. E., \& Law, C. W. (2011). What does recovery from schizophrenia mean? Perceptions of medical students and trainee psychiatrists. International Journal of Social Psychiatry, 57(3), 248-262.

Ng, R. M., Pearson, V., Lam, M., Law, C. W., Chiu, C. P., \& Chen, E. Y. (2008). What does recovery from schizophrenia mean? Perceptions of long-term patients. International Journal of Social Psychiatry, 54(2), 118-130.

O'Hagan, M. (2009). Leadership for empowerment and equality: A proposed model for mental health user/survivor leadership. International Journal of Leadership in Public Services, 5(4), 1-12.

Ralph, R. O., \& Corrigan, P. W. (2005). Recovery in mental illness: Broadening our understanding of wellness. Washington, DC: American Psychological Association.

Ridgway, P. A., Press, A., Ratzlaff, S., Davidson, L., \& Rapp, C. A. (2003). Report on field testing the recovery enhancing environment measure. Lawrence: University of Kansas School of Social Welfare, Office of Mental Health Research and Training.

Slade, M., \& Hayward, M. (2007). Recovery, psychosis and psychiatry: Research is better than rhetoric. Acta Psychiatrica Scandinavica, 116, 81-83.

Song, L.-Y., \& Hsu, S.-T. (2011). The development of the stages of recovery scale for persons with persistent mental illness. Research on Social Work Practice, 21(5), 572-581.

Starnino, V. R. (2009). An integral approach to mental health recovery: Implications for social work. Journal of Human Behavior in the Social Environment, 19, 820-842.

Sun, T.-L. C. (2008). Themes in Chinese psychology. Sinagapore: Cengage Learning Asia Pte.

Tohen, M., Hennen, J., Zarate, C. M., Jr., Baldessarini, R. J., Strakowski, S. M., Stoll, A. L., et al. (2000). Two-year syndromal and functional recovery in 219 cases of first-episode major affective disorder with psychotic features. American Journal of Psychiatry, 157(2), 220-228.

Tse, S., \& Barnett, S. (2008). Organisational changes toward recovery oriented services. In C. Lloyd \& R. King (Eds.), Clinical management in mental health services (pp. 94-114). Australia: Blackwell Publishing.

Tse, S., Cheung, E. F. C., Kan, A., Ng, R. M.,\& Yau, S. (in press). Recovery in Hong Kong: Service user participation in mental health services. International Review of Psychiatry.

Tse, S., Davies, M., \& Li, Y. (2010). Chinese migrants with mental health problems and use of the Strengths Model. American Journal of Psychiatric Rehabilitation, 13(3), 171-188.

Warner, R. (2010). Does the scientific evidence support the recovery model? Psychiatrist, 34, 3-5.

Wood, A. L., \& Wahl, O. F. (2006). Evaluating the effectiveness of a consumer-provided mental health recovery education presentation. Psychiatric Rehabilitation Journal, 30(1), 46-53.

World Health Organization. (2005). Mental health atlas. Geneva: World Health Organization.

Yip, K. S. (2004). Taoism and its impact on mental health of the Chinese communities. International Journal of Social Psychiatry, 50(1), 25-42.

Yip, K. S. (2005). A strengths perspective in working with an adolescent with depression. Psychiatric Rehabilitation Journal, $28(4), 362-369$. 